\title{
A Comparative Study on Feto-Maternal Outcome of GDM Treated by Either Insulin or Metformin
}

\author{
NOOR T ${ }^{1}$, PARVIN MT $^{2}$, SAHA K ${ }^{3}$, BEGUM F $^{4}$, BANU SA5, TASNIM S ${ }^{6}$, JAHAN P ${ }^{7}$,
}

\begin{abstract}
:
Background: Gestational Diabetes Mellitus (GDM) is linked with amplified risk of variety of maternal and perinatal complications. There have been a number of studies comparing metformin with insulin in the management of GDM.

Methods: A clinical trial (Quasi experimental) was conducted on fifty women with GDM at their 24 - 34 weeks of gestation with the aim to compare maternal and perinatal outcomes treated by either insulin or metformin. The study population were recruited from obstetrics and gynaecology outpatient department of Medical College for Women and Hospital, Uttara, Dhaka, from July 2012 to December 2012. The patients were divided into two groups (nonrandomized), 25 patients in each, and were subjected to either injection insulin or oral metformin medication.
\end{abstract}

Results: The patients were grouped as insulin or metformin group. They were compared in terms of age, parity and developing maternal complications like preeclampsia $(p=0.24)$, UTI $(p=0.40)$, polyhydramnios $(p=0.70)$. However, the incidence of preterm birth was higher among metformin group in comparison to insulin group $(P=0.007)$. There was no significant difference between insulin and metformin group as regard to mode of delivery. The proportion of neonatal hypoglycemia in insulin group was higher than metformin group $(P=0.46)$ but statistically not significant. Other neonatal outcomes such as macrosomia, birth asphyxia and hyperbillirubinaemia did not differ significantly between two groups.

Conclusion: In women with GDM, treatment with metformin is associated with higher proportion of preterm birth than with insulin. Proportion of neonatal hypoglycemia is higher with insulin use.

Keywords: GDM, Insulin, Metformin, Maternal outcome, Fetal outcome.

Introduction:

Diabetes is a serious and growing global epidemic affecting more and more people worldwide and is particularly devastating when triggered during pregnancy. Maternal diabetes in pregnancy is a common medical complication of pregnancy and can

1. Tania Noor, FCPS (Obstetrics \& Gynae), Registrar, Dhaka Community Medical College \& Hospital.

2. Mst. Tahmina Parvin, FCPS FCPS (Obstetrics \& Gynae), Assistant professor of OBGYN, Dhaka Community Medical College \& Hospital.

3. Kakali Saha, FCPS,M.S (Obstetrics \& Gynae), Associate professor of OBGYN, Medical College for women \& Hospital ,Uttara, Dhaka.

4. Farjana Begum, FCPS FCPS (Obstetrics \& Gynae), Associate professor of OBGYN, Dhaka Community Medical College \& Hospital.

5. Selina Akter Banu, M.S FCPS (Obstetrics \& Gynae), Associate professor of OBGYN, Dhaka Community Medical College \& Hospital.

6. Saria Tasnim, FCPS FCPS (Obstetrics \& Gynae), Professor \& Head of OBGYN, Dhaka Community Medical College \& Hospital.

7. Parul Jahan, FCPS, M.S, DGO FCPS (Obstetrics \& Gynae), Professor \& Head of OBGYN, Medical College for women \& Hospital ,Uttara, Dhaka.

Address of Correspondence: Dr. Tania Noor, FCPS, Registrar of Obstetrics \& Gynae department, Dhaka Community Medical College \& Hospital, Baro Moghbazar, Wireless railgate, Dhaka. Phone: 017194444643, 01711817480, e-mail:noortania1983@gmail.com. 
lead to serious consequences for both the mother and the child ${ }^{1}$.

GDM constitutes $90 \%$ of all pregnancies complicated by diabetes ${ }^{2}$. According to American Diabetic Association (ADA), GDM affects $7 \%$ of all pregnancies, resulting in $>200,000$ cases per year ${ }^{3}$. The prevalence may range from $1-14 \%$ depending on the population sample and diagnostic criteria. It has been documented that there is marked variation in GDM prevalence among different racial and ethnic groups with higher prevalence in Native American, Asian and African-American population ${ }^{4}$. The prevalence of GDM among rural Bangladeshi women is $8.2 \%^{5}$.

If maternal normoglycemia cannot be achieved by diet and lifestyle changes, medication is needed. The standard treatment for achieving adequate glucose levels is insulin therapy. However, the disadvantages of insulin for the mother include the need for injections, risk of hypoglycemia, increased appetite and weight gain ${ }^{6}$. Furthermore, this treatment requires modification based on the patient's body mass index, glucose levels and lifestyle, ${ }^{7}$ and involves substantial costs of health education for the safe use of insulin and the cost of insulin-administration devices. Oral hypoglycemic agents have traditionally been avoided in pregnant women with diabetes because of the potential risks of neonatal hypoglycemia and teratogenicity associated with placental transfer to the fetus. Metformin is an anti-hyperglycemic agent which is not known to cause hypoglycemia in adult users. Metformin reduces hyperglycemia by suppressing hepatic glucose output (hepatic gluconeogenesis), increasing insulin sensitivity and enhancing peripheral glucose uptake. ${ }^{7,8}$ Metformin readily crosses the placenta in women with GDM, exposing the fetus to concentrations approaching those in the maternal circulation ${ }^{9}$,as well as in women with polycystic ovary syndrome ${ }^{10}$. However, metformin is not associated with fetal anomalies when used during the first trimester of pregnancy. ${ }^{11}$ In addition, metformin appears to be safe in the second and third trimesters of pregnancy. ${ }^{12}$ So objective of this study was to evaluate maternal and perinatal outcomes of pregnancy with GDM patients treated either by insulin or metformin.

\section{Materials \& Methods \\ Methodology:}

In this clinical trial (Quasi experimental),fifty antenatal women whose pregnancies had been complicated by GDM and did not respond to diet modification or nutritional instructions alone in 1 week, were recruited from gynae and obstetric outpatient department of Medical College for women and hospital, Uttara, Dhaka, from July 2012 to December 2012. The ethical committee approval was obtained. All participant assigned the informed consent. GDM was diagnosed at 20-36 weeks using WHO criteria : fasting plasma glucose $\geq 6.0 \mathrm{mmol} / \mathrm{L}$ and $2 \mathrm{~h}$ value $\geq 7.8 \mathrm{mmol} / \mathrm{L}$ following a $75 \mathrm{~g} \mathrm{OGTT}{ }^{13}$

Inclusion criterias were 20-35 years pregnant women with singleton pregnancy, the gestational age between 24-34 weeks, the gestational diabetes diagnosed for the first time during study period after 24 weeks gestation in a previously nondiabatic and having regular antenatal visits, the FBS level is $\geq 7.0$ $\mathrm{mmol} / \mathrm{L} \& 2 \mathrm{hrs}$ after $75 \mathrm{gm}$ OGTT $\geq 7.8 \mathrm{mmol} / \mathrm{L}$ after one week of diet therapy and no anatomical anomalies of fetus. The exclusion criteria were type 1 and type 2 diabetes, anyone who was already on insulin treatment, the lack of glycemic control even at the maximum dose of metformin, where insulin added or switch to insulin for glycemic control, any obstetric high risk conditions like multiple pregnancy, cardiovascular, renal, liver and thyroid disorders and recognized fetal anomaly by ultra sonogram.

Group 1 received short acting or combination of short and intermediate acting human insulin. Short acting insulin (Actrapid) was given as thrice daily injections before three meal and intermediate acting insulin given twice daily injections before breakfast and dinner. 24 hour insulin dose was estimated 0.7-1 unit $/ \mathrm{kg}$ body weight, in order to achieve the desired glycemic goal.

Group 2 received metformin orally initially at dose of $500 \mathrm{mg} /$ day with meals, which slowly increased up to $2500 \mathrm{mg}$ in divided doses as tolerated by the patient. If the target was not achieved with metformin alone, insulin was added. Metformin was stopped if maternal contraindication like liver and renal impairment developed and the targeted blood glucose level achieved. The dose increased $500 \mathrm{mg}$ weekly. Maternal age, BMI, fasting and 2 hours post prandial blood sugar were measured during the treatment was noted.

Monitoring was done at home by estimating blood glucose level at fasting and 2-hour postprandial after three main meals. The target of management was to maintain fasting blood sugar (FBS) at $<5.5 \mathrm{mmol} / \mathrm{L}$ 
and postprandial blood sugar levels at $<7 \mathrm{mmol} / \mathrm{L}$. Glycemic profile, fasting and postprandial blood sugar were done weekly for all cases. Dose modifications of drugs were made at each antenatal visit weekly till delivery. Standard obstetric care was accessible at the antenatal clinics including history taking, clinical examinations and some investigations like glycemic profile, ultra sonography, $\mathrm{HbA} 1 \mathrm{c}$ and other routine antenatal investigations. Neonatal assessment was done by clinical examination and laboratory investigations. Maternal outcomes including preeclampsia, polyhydramnios, infections, PPH and perinatal outcomes including prematurity, macrosomia ,birth asphyxia, perinatal asphyxia and hyperbilirubinemia were recorded, if any. Mode of delivery was also recorded.

Clinical properties between two groups were compared using student t-test and chi square test for continuous and categorical variables, respectively. The results are presented as mean \pm SD or absolute frequency in percentage. The significance level $<0.05$ was deemed as significant. The recorded data was evaluated using SPSS version ${ }^{12}$

\section{Results:}

Table I presents demographic variables. The mean age scores of insulin and metformin group were comparable $28+2.1$ years \& $29+2.5$ years, respectively $(p=0.21)$. The mean of parity in insulin group was $2 \pm 0.2$ and metformin group was $3 \pm 0.1$ $(p=0.19)$. Mean gestational age at entry were $27.5 \pm 2.8$ weeks and $32.0 \pm 0.6$ weeks respectively, in insulin and metformin group ( $p=0.491)$, difference is not significant. Moreover, the mean gestational age of preterm delivery was $36 \pm 0.7$ weeks in insulin group and $34.5 \pm 1.1$ weeks in metformin group , the difference were statistically significant $(P=0.007)$. Term delivery was $38 \pm 0.2$ weeks and $38 \pm 0.6$ weeks in insulin and metformin group respectively $(P=1.32)$, statistically not significant.
The maternal outcomes are presented in Table II. Of 25 subjects in insulin group 2 cases $(8 \%)$ and among 25 subjects in metformin group one case $(4 \%)$ developed preeclampsia. $(p=0.24)$. Four percent patients of both group developed polyhydramnios $(p=0.70)$. Urinary tract infection was found $4 \%$ and $8 \%$ for insulin and metformin groups respectively $(p=0.40)$. No significant difference was found between two groups regarding medical disorders which developed during antenatal period.

Table III shows mode of delivery among the studied groups. Vaginal delivery was in $12 \%$ and $16 \%$ of insulin and metformin groups respectively $(p=0.46)$, statistically not significant. Caesarian section done in $88 \%$ and $84 \%$ of insulin and metformin groups respectively $(p=0.68)$, the difference was not significant between two groups.

Table IV shows maternal postpartum complications. Of 25 subjects of insulin and metformin groups two cases $(8 \%)$ and 4 cases (16\%) developed $\mathrm{PPH}$ $(p=0.50)$ respectively. Moreover, UTI and wound infection were $8 \%$ \& $4 \%$ in insulin group and $4 \% \& 8 \%$ in metformin group respectively $(p=0.59)$. There were no significant differences between the two studied groups regarding postpartum complications of GDM patients.

Perinatal outcomes in insulin and metformin groups are shown in Table V. Prematurity in metformin group was significantly higher (16\%) than in insulin group $4 \%(p=0.007)$. Neonatal hypoglycemia $(<1.6 \mathrm{mmol} /$ L) developed among $20 \%$ babies of patients who treated with insulin whereas it was $12 \%$ in metformin group $(p=0.46)$. Difference was not statistically significant. The incidence of macrosomia, birth asphyxia and neonatal hyperbilirubinaemia in insulin group were $8 \%, 8 \%$ and $16 \%$ respectively, while in metformin group were $4 \%, 4 \%$ and $8 \%$ respectively. The rates of macrosomia, birth asphyxia and neonatal hyperbilirubinaemia were similar between two groups.

Table-I

Base line criteria of mother

\begin{tabular}{lccc}
\hline Variables & $\begin{array}{c}\text { Insulin Group } \\
(\mathrm{n}=25) \\
\text { Mean }( \pm \mathrm{SD})\end{array}$ & $\begin{array}{c}\text { Metformin Group } \\
(\mathrm{n}=25) \\
\text { Mean }( \pm \mathrm{SD})\end{array}$ & P Value \\
\hline Age (Years) & $28 \pm 1.1$ & $29 \pm 2.5$ & \\
Parity & $2 \pm 0.2$ & $3 \pm 0.1$ & 0.21 \\
Gestational age at entry/week & $27.5 \pm 2.8$ & $32.0 \pm 0.6$ & 0.19 \\
Gestational age at delivery/week & & & 0.49 \\
Preterm (<37 weeks) & $36 \pm 0.7$ & $34.5 \pm 1.1$ & 0.007 \\
Term ( $\leq 37$ weeks $)$ & $38 \pm 0.2$ & $38 \pm 0.6$ & 1.32 \\
\hline
\end{tabular}


Table-II

Antenatal outcomes of mother

\begin{tabular}{|c|c|c|c|c|c|c|}
\hline \multirow[t]{2}{*}{ Variables } & \multicolumn{2}{|c|}{$\begin{array}{c}\text { Insulin Group } \\
(\mathrm{n}=25)\end{array}$} & \multicolumn{2}{|c|}{$\begin{array}{l}\text { Metformin Group } \\
(\mathrm{n}=25)\end{array}$} & \multirow[t]{2}{*}{$\mathrm{X}^{2}$ value } & \multirow[t]{2}{*}{ P Value } \\
\hline & No & $\%$ & No & $\%$ & & \\
\hline Preeclampsia & 2 & 8 & 1 & 4 & 1.33 & 0.24 \\
\hline Polyhydramnios & 1 & 4 & 1 & 4 & 0.13 & 0.70 \\
\hline UTI & 1 & 4 & 2 & 8 & 0.23 & 0.40 \\
\hline
\end{tabular}

Table-III

Mode of delivery between two groups

\begin{tabular}{|c|c|c|c|c|c|c|}
\hline \multirow[t]{2}{*}{ Mode of delivery } & \multicolumn{2}{|c|}{$\begin{array}{c}\text { Insulin Group } \\
(\mathrm{n}=25)\end{array}$} & \multicolumn{2}{|c|}{$\begin{array}{l}\text { Metformin Group } \\
\qquad(\mathrm{n}=25)\end{array}$} & \multirow[t]{2}{*}{$\mathrm{X}^{2}$ value } & \multirow[t]{2}{*}{ P Value } \\
\hline & No & $\%$ & No & $\%$ & & \\
\hline Vaginal delivery & 3 & 12 & 4 & 16 & 2.56 & 0.46 \\
\hline Caesarean section & 22 & 88 & 21 & 84 & 0.16 & 0.68 \\
\hline
\end{tabular}

Table-IV

Postpartum complications of mother between two groups

\begin{tabular}{|c|c|c|c|c|c|c|}
\hline \multirow[t]{2}{*}{ Variables } & \multicolumn{2}{|c|}{$\begin{array}{l}\text { Insulin Group } \\
\quad(n=25)\end{array}$} & \multicolumn{2}{|c|}{$\begin{array}{l}\text { Metformin Group } \\
(\mathrm{n}=25)\end{array}$} & \multirow[t]{2}{*}{$\mathrm{X}^{2}$ value } & \multirow[t]{2}{*}{ P Value } \\
\hline & No & $\%$ & No & $\%$ & & \\
\hline $\mathrm{PPH}$ & 2 & 8 & 4 & 16 & 1.67 & 0.52 \\
\hline UTI & 2 & 8 & 1 & 4 & 1.02 & 0.59 \\
\hline Wound infection & 1 & 4 & 2 & 8 & 1.02 & 0.59 \\
\hline
\end{tabular}

Table-V

Perinatal outcomes between two groups

\begin{tabular}{|c|c|c|c|c|c|c|}
\hline \multirow[t]{2}{*}{ Variables } & \multicolumn{2}{|c|}{$\begin{array}{l}\text { Insulin Group } \\
(\mathrm{n}=25)\end{array}$} & \multicolumn{2}{|c|}{$\begin{array}{l}\text { Metformin Group } \\
(\mathrm{n}=25)\end{array}$} & \multirow[t]{2}{*}{$\mathrm{X}^{2}$ value } & \multirow[t]{2}{*}{ P Value } \\
\hline & No & $\%$ & No & $\%$ & & \\
\hline Preterm baby & 1 & 4 & 4 & 16 & 7.20 & 0.007 \\
\hline Macrosomia & 2 & 8 & 1 & 4 & 1.33 & 0.24 \\
\hline Birth asphyxia & 2 & 8 & 1 & 4 & 1.33 & 0.24 \\
\hline Hypoglycemia & 5 & 20 & 3 & 12 & 2.57 & 0.46 \\
\hline Hyperbilirubinemia & 4 & 16 & 2 & 8 & 2.66 & 0.10 \\
\hline
\end{tabular}

\section{Discussion:}

Gestational Diabetes Mellitus (GDM) has been described as any extent of glucose intolerance with onset or first recognition during pregnancy ${ }^{14}$. It is one of the most common medical complications of pregnancy which is related to numerous adverse complications to mother and higher risk of perinatal morbidity \& mortality.
Traditionally, insulin therapy had been considered standard practice for women with GDM who could not have been controlled by nutritional therapy and physical excersise ${ }^{15}$. Insulin therapy can be difficult for pregnant women due to multiple injection requirements, risk of hypoglycemia, and need for dose modification and weight gain. Metformin is an alternative to insulin and is effective in the treatment 
of women with GDM ${ }^{16}$. It improves peripheral insulin resistance, decreases hepatic gluconeogenesis and is not associated with weight gain or hypoglycemia ${ }^{17}$.

The controversy of using oral hypoglycemic agent in pregnancy is related to concerns about their safety for the development of fetus. Therefore, evaluation of the effect of metformin and insulin in glycemic control and pregnancy outcomes in GDM women were done.

Preterm delivery less than 37 weeks was more in metformin group. Mean gestational age of preterm delivery in insulin group was $36 \pm 0.7$ weeks and metformin group was $34.5 \pm 1.1$ weeks, that was found to be statistically significant $(p=0.007)$. This is in contrast to the MiG trial, where preterm births were significantly higher in the metformin group $(p=0.04)$ 18 . There was no obvious explanation for this finding. Other studies reporting outcomes in women treated with metformin do not show an increase in preterm deliveries ${ }^{19,20}$. Niromanesh $\mathrm{S}$ et al. found that the incidence of preterm delivery was twofold higher in metformin group but this was not statistically significant ${ }^{21}$. On the contrary, Balani previously showed that preterm delivery was more common in the insulin group ${ }^{20}$. Mean gestational age at birth was $38 \pm 0.2$ in insulin group and $38 \pm 0.6$ in metformin group ( $p=1.32)$. Gandhi $P$ et al. found that mean gestational age at birth was statistically higher in the metformin group (38.7 \pm 1.31$)$ weeks, but $(38.3 \pm 1.9)$ weeks in insulin group 22 .

In our study the rate of preeclampsia in insulin group was $8 \%$ and in metformin group it was $4 \%$. However, this was not significant difference. In consistent with our finding, Rowan et al., Tertti et al. and also Spaulonci et al., have been reported similar results $23,24,25$. It is notable that despite there was no significant difference in preeclampsia rate between two groups, it's rate was lower in metformin group. In Spaulonci's study the rate of preeclampsia in metformin group was higher than in insulin group; however it was not significant ${ }^{25}$. We found that other maternal outcomes including polyhydamnios, UTI, postpartum hemorrhage and caesarian wound infection did not differ significantly between two groups.

Regarding mode of delivery, there was no difference in the mode of delivery between the two groups; this is in agreement with most authors. The rate of cesarean section was much higher $43(86 \%)$ than vaginal delivery $07(14 \%)$ in both groups. The rate of cesarean deliveries reported by Silva JC et al. was $70 \%$. Such high rates are common in some low resource countries ${ }^{26}$. In this study, comparison between the two study groups regarding C.S. were found $22(88 \%$ ) and $21(84 \%)$ for insulin and metformin groups respectively. There were no statistically significant differences between the two study groups $(p=0.68)$. Moore et al. found $89 \%$ of insulin group and $83 \%$ of metformin group delivered by caesarean section ${ }^{27}$. ljas $\mathrm{H}$ et al. found that there were more caesarean deliveries $(38 \%)$ in the metformin group than in the insulin group ${ }^{19}$.

In the present study preterm delivery occurred in 4 cases $(16 \%)$ for metformin group and 1 case $(4 \%)$ for insulin group. The difference was found to be statistically significant $(p=0.007)$. In MiG trial preterm birth were significantly higher in metformin group $(p=0.04)$, the iatrogenic prematurity rate was not different between the metformin and insulin group, but there was a trend to more spontaneous prematurity in the metformin group 18 . Birth asphyxia was found 2 cases ( $8 \%$ ) and 1 case (4\%) in insulin and metformin group respectively, statistically not significant $(p=0.24)$. Respiratory distress in newborn did not differ between the two treatment groups in MiG trial ${ }^{18}$. There were 2 cases $(8 \%)$ with birth weight more than or equal to $4 \mathrm{~kg}$, (macrosomia) in the insulin group and 1 case $(4 \%)$ with that weight in the metformin group, $(p=0.24)$, which is statistically not significant. Similarly Gandhi $P$ et al. found that the women in metformin group had a significantly lower rate of macrosomia $(8.2 \%$ vs. $14.3 \%)^{22}$.

Hypoglycemia frequently occurs in newborns of women with GDM. In the present study, the rate of neonatal hypoglycemia in insulin group was slightly higher $(20 \%)$ than metformin group $(12 \%)$, but not statistically significant $(p=0.46)$. lja's $\mathrm{H}$ et al. found that the frequency of neonatal hypoglycemia were slightly but not significantly higher in insulin group 19 . Tertti et al. found significantly fewer neonates with hypoglycemia in metformin group 24 .

Hyperbilirubinaemia was found in 4 cases (16\%) and 2 cases $(8 \%)$ of insulin and metformin group respectively, there were no statistical, significant differences between the two studied groups $(p=2.66)$. Coetzee et al. noted a higher incidence of neonatal hyperbilirubinaemia in the metformin group 28 . 


\section{Conclusion:}

This study findings indicate that though metformin is a logical treatment for women with gestational diabetes mellitus, but in some aspect higher maternal and perinatal complications were observed than insulin. So, controversy surrounds the ideal approach for treating GDM with oral agents, need further study to validate this result.

\section{References:}

1. James DK, Steer PJ, Weinier CP, Gonik B. Gestational Diabetes Mellitus. In:Thome E. Spong EY. High risk pregnancy management options. $4^{\text {th }}$ edition. W.B. Saunders 2011: $665-681$.

2. Chamberlain G, Steer P Johnson M, Chang A. Gestational Diabetes. In:Landon MB, Land B. Turnbull's obstetrics. $3^{\text {rd }}$ edition. Churchill Livingstone, London, 2002: 277 - 330.

3. Cunningham G, Gant N, Leveno K, Gilstra PL. Endocrine disease and pregnancy. In:Rasmussen KM, Yaktine AL. Williams Obstetrics. $21^{\text {th }}$ edition. Oxford University Press; 2001: 1360 - 1368.

4. Tracy L, Setji MD, Ann J, Brown MD, Mark N, Feinglos MD. Gestational diabetes Mellitus and its outcome. Clinical Diabetes 2010; 23(3): 17-24.

5. Sayeed MA. Mahtab H, Khanam PA, Amin STE and Azad K. Prevalence of gestational diabetes in a rural community of Bangladesh. Diabetic medicine 2005; 22(9): 1267-7.

6. United Kingdom Prospective Diabetes Study (UKPDS) Relative efficacy of randomly allocated diet, sulphonylurea, insulin or metformin in patients with newly diagnosed non-insulin dependent diabetes followed for three years. BMJ 1995; 310:83-8.

7. Rowan JA, Rush EC, Obolonkin V, Battin M, Wouldes T, Hague WM. Metformin in gestational diabetes: the offspring follow-up (MiG TOFU): body composition at 2 years of age. Diabetes Care 2011; 34:2279-84.

8. Kirpichnikov D, McFarlane SI, Sowers JR. Metformin: an update. Ann Intern Med 2002; 137:25-33.

9. Charles B, Norris R, Xiao X, Hague W. Population pharmacokinetics of metformin in late pregnancy. The Drug Monit. 2006; 28:67-72.

10. Vanky E, Zahlsen K, Spigset O, Carlsen SM. Placental passage of metformin in women with polycystic ovary syndrome. Fertil Steril. 2005; 83:1575-78.

11. Gilbert C, Valois M, Koren G. Pregnancy outcome after first-trimester exposure to metformin: a meta-analysis. Fertil Steril. 2006; 86:658-63.

12. Nanovskaya TN, Nekhayeva IA, Patrikeeva SL, Hankins GD, Ahmed MS. Transfer of metformin across the dually perfused human placental lobule. Am J Obstet Gynecol 2006; 195: 1081-5.

13. "IADPSG Consensus Panel International association of diabetes and pregnancy study groups recommendations on the diagnosis and classification of hyperglycemia in pregnancy," Diabetes Care 2010; 33(3): 676-682.

14. Korucuoglu U, Biri A, Turkyilmaz E, DogaYildirim F, IlhanM, Hirfanoglu IM, et al. Glycemic levels with glucose loading test during pregnancy and its association with maternal and perinatal outcomes. Diabetes Res Clin Pract. 2008; 80:69-74.

15. Nicholson W, Baptiste-Roberts K. Oral hypoglycemic agents during pregnancy: The evidence for effectiveness and safety. Best Pract Res Clin Obstet Gynaecol 2011; 25: 51-63.

16. Glueck CJ, Goldenberg N, Wang P, Loftspring M, Sherman A. (2004) Metformin during pregnancy reduces insulin, insulin resistance, insulin secretion, weight, testosterone, and development of gestational diabetes: prospective longitudinal assessment of women with polycystic ovary syndrome from preconception throughout pregnancy. Hum Reprod.2004; 19: 510-21.

17. Wensel TM. Role of metformin in the treatment of gestational diabetes. Ann Pharmacother. 2009; 43: 939-943.

18. Rowan JA, Gao W, Hague WM, Mclntyre HD. Glycemia and its relationship to outcomes in the metformin in gestational diabetes trial. Diabetes Care 2010; 33: 9-16. 
19. Ijas $H$, Vaarasmaki M, Morin-Papunen L, Keravuo R, Ebeling T, et al. Metformin should be considered in the treatment of gestational diabetes: a prospective randomised study. BJOG 2011; 118: 880-885.

20. Balani J, Hyer SL, Rodin DA, Shehata H. Pregnancy outcomes in women with gestational diabetes treated with metformin or insulin: a case-control study. Diabet Med. 2009; 26: 798-802.

21. Niromanesh S, Alavi A, Sharbaf FR, Amjadi N, Moosavi S, Akbari S. Metformin compared with insulin in the management of gestational diabetes mellitus: a randomized clinical trial. Diabetes Res Clin Pract. 2012; 98(3): 422-9.

22. Gandhi P, Bustani R, Madhuvrata P, Farrell T.E .Introduction of metformin for gestational diabetes mellitus in clinical practice: Has it had an impact? Eur J Obstet Gynecol Reprod Biol.2012; I60(2): 147-50.

23. Jenet A. Rowan, William M, Hague, Wanzhen G, Malcolm R, Battin, M. Peter Moore. Metformin versus insulin for the treatment of Gestational Diabetes. N Engl J Med 2008; 35:19-29.
24. .Tertti, K., Ekblad, U., Vahlberg, T., Rönnemaa, T. Comparison of Metformin and Insulin in theTreatment of Gestational Diabetes: A Retrospective, Case-Control Study. The Review of Diabetic StudiesRDS 2008;5(2):95-101.

25. Spaulonci, C. P., Bernardes, L. S., Trindade, T. C., Zugaib M., \& Francisco R. P. Randomized trial of metformin vs insulin in the management of gestational diabetes. American journal of obstetrics and gynecology 2013;209(1), 34.e31-37.

26. Silva JC, Fachin DR, Coral ML, Bertini AM. Perinatal impact of the use of metformin and glyburide for the treatment of gestational diabetes mellitus. J Perinat Med. 2012; 40(3): 225-8.

27. Moore, L. E., Briery, C. M., Clokey, D., Martin, R. W., Williford, N. J., Bofill, J. A., Morrison, J. C. Metformin and insulin in the management of gestational diabetes mellitus: Preliminary results of a comparison. The Journal of reproductive medicine 2007; 52(11): 1011-1015.

28. Coetzee EJ, Jackson WP. Metformin in management of pregnant insulin independent Diabetics. Diabetologia 2008;16:241-5. 